\title{
Lifestyle Characterization in Mexican Teenagers: Healthy Weight against Overweight and Obesity
}

\section{Sonia González González ${ }^{1}$ (D), Patricia Cruz Bello ${ }^{1}$, María de Lourdes García Hernández¹, María Alberta García Jiménez ${ }^{2}$, Gabriela Yanet Cortés Moreno ${ }^{3}$}

\author{
${ }^{1}$ Facultad de Enfermería y Obstetricia, Universidad Autónoma del Estado de México, Toluca, México \\ ${ }^{2}$ Universidad Autónoma Metropolitana, México City, México \\ ${ }^{3}$ Hospital Regional de Alta Especialidad Ixtapaluca, Ixtapaluca, México \\ Email: soniagonzalez22@yahoo.com.mx,patriciacruzbello@yahoo.com.mx, luygaba@yahoo.com.mx, \\ ajimenez@correo.xoc.uam.mx, medic_gaby@live.com.mx
}

How to cite this paper: González, S.G., Bello, P.C., Hernández, M. de L.G., Jiménez, M.A.G. and Moreno, G.Y.C. (2021) Lifestyle Characterization in Mexican Teenagers: Healthy Weight against Overweight and Obesity. Open Journal of Nursing, 11, 28-41. https://doi.org/10.4236/ojn.2021.111004

Received: November 20, 2020

Accepted: January 18, 2021

Published: January 21, 2021

Copyright $\odot 2021$ by author(s) and Scientific Research Publishing Inc. This work is licensed under the Creative Commons Attribution International License (CC BY 4.0).

http://creativecommons.org/licenses/by/4.0/

\section{(c) (i) Open Access}

\begin{abstract}
Objective: Currently Mexico is one of the 1st places in overweight and obesity in teenagers; the health and nutrition national survey in 2018, expresses a $41.1 \%$ of women in teenager's population and a $35.8 \%$ in men. To analyze teenagers' lifestyles with healthy weight against overweight and obesity. $\mathrm{Me}$ thod: Descriptive, transverse, analytic and comparative, a non-probabilistic sampling distributed up to convenience in 2 groups of cases and controls, with 50 teenagers diagnosed with overweight and obesity and 50 teenagers with healthy weight, in a 12 to 15 years old age range; for previous informed consent, the survey Health-Promoting Lifestyle Profile II was applied to measure the lifestyles in 6 dimensions. The analysis got a standard deviation and the association of variables $U$ of Mann-Whitney for independent samples. Results. In both teenagers' groups male gender prevailed with a $76 \%$, the result in teenagers' group was identified, an average lifestyle with the dimensions of: interpersonal relationships, feeding, physical activity, stress management and spiritual growth and a low level in the dimension of health responsibility. There is a meaningful difference in the variables association in the spiritual growth lifestyle. Conclusions: The evaluation of both groups is similar to an average score; this shows that there is a risk to unleash overweight, obesity and complications in the adult age of the teenager.
\end{abstract}

\section{Keywords}

Lifestyle, Teenagers, Healthy Weight, Overweight and Obesity 


\section{Introduction}

The World Health Organization defines lifestyles like "the perception an individual has of his existence place, the culture context and the values system in which he lives and its relation with his objectives, his expectations, his regulations, his concerns"; these styles are modified by changes of social, economic, cultural and psychological kind to which teenagers have to during their process of development and that can affect in their academic performance [1]. Currently the word "lifestyle" refers to the way to eat, work out, rest, play, behave with others, sleep or work, among other aspects of the way of living [2]; it means, a specific lifestyle implies the conscious or unconscious selection of one or another kind of behavior, which can persuade or protect before a lot of sicknesses [3]. In the developed countries, the lifestyle is one of the biggest determinants over which the health state of the population affects mainly in the death toll [4]; such changes are presented in an accelerated way, and the health professionals have minimized the complications of this fact in health of the Mexican population. There is an unbalance between the minority budget dedicated to interventions about lifestyle and its main importance in the population's health [5] [6]. Intervening to improve the patients' lifestyle seems to be an objective clearly justified [7]. Scientific literature supports the effectiveness of such interventions on the lifestyle to reduce the risk of presenting a chronic disease as well as to intervene in the therapeutic care of existing health problems, which is known as "lifestyle medicine" [8]. Nevertheless, lifestyle medicine does not pretend to be an exclusive alternative, rather a complementary strategy to the usual treatments [7] [9]. The different detrimental lifestyle aspects for health are not presented isolated, rather they agree on and get powered [3]. Fortunately, the same happens with the healthy lifestyle ingredients [10]. In this way, promoting various healthy lifestyles simultaneously is shown useful due to its synergic action [3].

Currently, many studies determine that lifestyle changes are effective to improve people's health and reduce sickness charge [11] [12]. The useful strategies to evince the Behavioral Change Intervention (BCI), are the cognitive-behavioral [13]. Pender expressed that the behavior is encouraged by the desire of reaching the wellbeing and the human potential. He got interested in the creation of a nursing model which gave response to the way of how people adopt decisions about the care of their own health [10]. It integrates different theories: learning theory of Bandura (1977), who postulates the importance of cognitive processes in behavior change, also the social learning theory, currently called social cognitive theory, which includes; self-beliefs, self-attribution, self-evaluation and self-efficacy. It also integrates the expectation assessment model of human motivation described by Feater (1982), who asserts that the behavior is rational and economic [14]. Taking as reference this last theory, Pender creates an instrument together with Walker and Sechrist in 1987, having as base a psychometric scale; promotion of the lifestyle-lifestyle--health behavior-communication 
strategy, which validated its Spanish version in 1990 [15]. The Health Promoting Lifestyle Profile II, is an instrument published in Spanish with a variety of $45.9 \%$ and a reliability between 0.7 and 0.9 . The scale validated in the Latin-American context with an alpha of Cronbach of 0.93 and its validity reported by factorial analysis of the principal components, has been used in Colombian women in the Triviño study in 2007 [16].

A problem in health that requires an immediate intervention in vulnerable groups is overweight and obesity in teenagers, situation that has increased in all the world through the last decades. Mexico is a developing country that generates great changes in health, one of them is the complications of persons with overweight and obesity in early age. The epidemiologic numbers show that in 2016 there were more than 340 million children and teenagers from 5 to 19 years with overweight or obesity, the prevalence of this pathology has increased in an amazing way, from $4 \%$ in 1975 to more than $18 \%$ in 2016. The most current statistics such as the National Health Survey and Nourishment 2018 says that a $3.5 \%$ increased superior to the one observed in 2012, this difference is statistically meaningful. In 2012 the national prevalence of overweight in children and teenagers of female gender was $23.7 \%$ and in male gender was $19.6 \%$, in the same year the obesity in women was $12.1 \%$ and in men was $14.5 \%$. By 2018 the number increased the overweight in female gender by $27.0 \%$ and in male gender was $20.7 \%$. The combined prevalence of overweight and obesity in 2018 in men was $35.8 \%$ and in women $41.1 \%$ [11].

Nowadays there are more people with overweight and obesity rather than malnourishment, by such reason, the public policies favor malnourishment prevention, and few countries including Mexico take care of developing policies to fight overweight and obesity through healthy lifestyle changes.

According to which was contemplated there's an identified national problem in nourishment, consequently analyzing healthy lifestyles in teenagers is of great importance to prevent complications in adult life. In terms of the principal objective of this research, it was to analyze the teenagers' lifestyles with healthy weight before overweight and obesity.

\section{Materials and Methods}

\subsection{Surveyed and Estimation of the Simple Size}

After a descriptive, transverse, analytic and comparative study, the lifestyles of teenagers with overweight, obesity and healthy weight were typified. A non-probabilistic sampling distributed up to convenience in 2 groups of cases and controls. The size of the sample was determined taking the Body Mass Index (IMC) in students of a junior high school in Mexico, 50 were diagnosed with body mass index percentile superior to 85 , the rest resulted in in a healthy weight, in such way that a homogeneous sample in age and sex of 50 teenagers with healthy weight and 50 teenagers with overweight and obesity, previous authorization and informed consent. 


\subsection{Survey Tools}

Previous authorization of the author, the instrument Health-Promoting Lifestyle Profile II was applied, formed by 2 sections; the first one was with sociodemographic data; age, sex, weight and the second formed with 52 items distributed in six dimensions: health responsibility, physical health, nourishment, spiritual growth, interpersonal relationships and stress management [17]. The dimensions are conceptualized in the next way: Responsibility in health, giving attention to the own health, one's own education about health, the act of informing and searching professional help [17]. Physical activity, is the regular participation in light activities, moderated or strenuous, inside a planned and controlled program for the wellness of the aptitude and health or incidentally as part of the daily life or leisure activities [17]. Nourishment, is the dimension that implies the selection, knowledge and food consumption essential for the support, health and wellbeing. It's included the selection of a daily healthy diet consistent with directives of the food pyramid guide [17]. Spiritual growth, it's centered in the development of internal resources that is made through transcending, connecting and developing to be balanced beings with inner peace. It's a feeling of harmony, fullness, and the connection of the universe. Interpersonal relationships, it refers to the use of communication to make a feeling of intimacy and meaningful closeness, there's an exchange of ideas and feelings through verbal and non-verbal messages [17]. Stress management, is de-identification and mobilization of psychological and physical resources to effectively control or to reduce the tension.

The items were valued through the Likert scale that goes from 1 to 4 where 1 ( $\mathrm{N}=$ never), 2 (Sometimes), 3 ( $\mathrm{F}=$ Frequently), $4(\mathrm{R}=$ Routinely). The summation of the items values each dimension, by consolidating it you have the results of healthy lifestyles. It's important to mention that the instrument has the rate of reliability alpha for the total scale of 0.93 and test-retest reliability was 0,86 : the alpha rates of Cronbach. For the interpretation of each dimension, the summation of the answers was made; determining the frequency with which the surveyed one makes the investigated behavior in each item. According to the assessment of the instrument: the deliberation from 52 to 104 items is considered a low lifestyle, that refers to an unhealthy lifestyle, from 105 to 156 items it's an average lifestyle, it infers to the individual's health with some alterations referring to his health and from 157 to 208 items it's a high healthy lifestyle, this shows the teenager presents an optimal lifestyle in his health.

\subsection{Statistical Analysis}

For the statistical analysis the ordinal variables were expressed with average central tendency and to contrast the variables $U$ of Mann-Whitney was used for two independent samples. The investigation was approved by the Investigation and Ethics Committee in Investigation of the Regional Hospital of High Specialty in Ixtapaluca, state of Mexico, with registration number NR-019.2017. 


\section{Results}

\subsection{General Information of the Investigation Obeject}

Out of the 100 participating adolescents from the high school in the east zone of State of Mexico, it was searched to have each group of homogeneous participants with a total of 50 with overweight and obesity, and the other 50 with a healthy weight (control group that is similar in age and gender)

\subsection{Group Lifestyle Descriptions}

In Chart 1, the predominant gender was the male in both groups with a percentage of $76 \%$. The average age in both groups was of 12 years with $30 \%, 13$ years with $20 \%, 14$ years with $48 \%$ and 15 years with $2 \%$.

In Chart 2 and Chart 3, it's shown the descriptive statistic of the cases and controls, it shows that the interpersonal relationships dimension, shows a predominant behavior in the frequency of 1.64 of the median in teenagers with overweight and obesity, and with a median of 1.54 of teenagers with healthy weight, both groups show that they're directed to the results of an average lifestyle.

Chart 1. Age frequency and sex in teenagers group.

\begin{tabular}{|c|c|c|c|c|c|c|}
\hline \multirow{2}{*}{$\begin{array}{c}\text { Teenagers } \\
\text { Age }\end{array}$} & \multicolumn{6}{|c|}{ Healthy weight/overweight and obesity (homogeneous groups in age and gender) } \\
\hline & Female & $\%$ & Male & $\%$ & Total & $\%$ Total \\
\hline 12 & 4 & 8 & 11 & 22 & 15 & 30 \\
\hline 13 & 6 & 12 & 4 & 8 & 10 & 20 \\
\hline 14 & 2 & 4 & 22 & 44 & 24 & 48 \\
\hline 15 & - & - & 1 & 2 & 1 & 2 \\
\hline Total & 12 & 24 & 38 & 76 & 50 & 100 \\
\hline
\end{tabular}

Source: Obtained data of HPLP instrument, 2019.

Chart 2. Healthy weight teenagers group.

\begin{tabular}{|c|c|c|c|c|c|c|c|c|c|c|}
\hline \multirow{3}{*}{ Dimensions } & \multirow{3}{*}{$n$} & \multirow{3}{*}{$x$} & \multirow{3}{*}{ minimum } & \multirow{3}{*}{ maximum } & \multicolumn{6}{|c|}{ Dimensions Assessment } \\
\hline & & & & & \multicolumn{2}{|l|}{ High } & \multicolumn{2}{|l|}{ Medium } & \multicolumn{2}{|l|}{ High } \\
\hline & & & & & Frequency & $\%$ & Frequency & $\%$ & Frequency & $\%$ \\
\hline 1. Interpersonal Relations & 50 & 1.54 & 1 & 3 & 24 & 48 & 25 & 50 & 1 & 2 \\
\hline 3. Health Responsibility & 50 & 1.40 & 1 & 3 & 36 & 64 & 16 & 32 & 2 & 4 \\
\hline 4. Physical Activity & 50 & 1.72 & 1 & 3 & 23 & 46 & 18 & 36 & 9 & 18 \\
\hline 5. Stress Management & 50 & 1.76 & 1 & 3 & 19 & 38 & 24 & 48 & 7 & 14 \\
\hline 6. Spiritual Growth & 50 & 1.88 & 1 & 3 & 17 & 34 & 22 & 44 & 11 & 22 \\
\hline
\end{tabular}

Source: Obtained data of HPLP instrument, 2019. 
Chart 3. Overweight and obesity teenagers group.

\begin{tabular}{|c|c|c|c|c|c|c|c|c|c|c|}
\hline \multirow{3}{*}{ Dimensions } & \multirow{3}{*}{$n$} & \multirow{3}{*}{$x$} & \multirow{3}{*}{ minimum } & \multirow{3}{*}{ maximum } & \multicolumn{6}{|c|}{ Dimensions Assessment } \\
\hline & & & & & \multicolumn{2}{|l|}{ High } & \multicolumn{2}{|l|}{ Medium } & \multicolumn{2}{|l|}{ High } \\
\hline & & & & & Frequency & $\%$ & Frequency & $\%$ & Frequency & $\%$ \\
\hline 1. Interpersonal Relations & 50 & 1.64 & 1 & 3 & 21 & 42 & 26 & 52 & 3 & 6 \\
\hline 2. Nutrition & 50 & 1.80 & 1 & 3 & 13 & 26 & 34 & 68 & 3 & 6 \\
\hline 3. Health Responsibility & 50 & 1.40 & 1 & 3 & 31 & 62 & 18 & 36 & 1 & 2 \\
\hline 4. Physical Activity & 50 & 1.66 & 1 & 3 & 22 & 44 & 23 & 46 & 5 & 10 \\
\hline 5. Stress Management & 50 & 1.72 & 1 & 3 & 16 & 32 & 32 & 64 & 2 & 4 \\
\hline 6. Spiritual Growth & 50 & 2.16 & 1 & 3 & 6 & 12 & 30 & 60 & 14 & 28 \\
\hline
\end{tabular}

Source: Obtained data of HPLP instrument, 2019.

Both groups show and express in the dimension of interpersonal relationships with low frequency to talk or discuss problems and worries with people close to them, this shows that there is no effective communication with the people close to them, it can be family, friends or acquaintances. It also refers that to be touched or to touch people close to them is very difficult for them, they don't allow to be hugged or to express any feeling like a handshake.

The group of teenagers with healthy weight presents a low score on having meaningful and enriching relationships, besides looking for the way to fill their needs. Teenagers with overweight and obesity manifest with a low level easily praising to other people for their successes and it's easy for them to show worry, love and affection to others, this represents that the transition of the teenager when relating with his surroundings is hard, therefore an education intervention that allows relating with confidence with the others is needed.

In the dimension of nourishment, the predominance of the teenagers' median with overweight and obesity is 1.80 and the one of the teenagers with a healthy weight is 1.76 , both corresponding to the average lifestyle frequency. Both groups express nourishment problems in negative answers when picking a diet low in fat, saturated fat and cholesterol, as well as reading the nourishing tags to identify the caloric value, the fat content and sodium in packed and processed food. The group with overweight and obesity refers low frequency when eating from 6 to 11 portions of bread, cereals, rice or pasta (noodles) everyday, it means, the case group shows that its nourishment is uncontrolled and a little healthy.

For the dimension of health responsibility, the frequency of a standard deviation of 1.40 prevailed in teenagers with overweight and obesity and $1.40 \mathrm{pf}$ the teenagers with healthy weight, indicating the result of low lifestyles, this shows that the health of teenagers is expressed compromised in both groups.

The answers with low score in this dimension relate that teenagers do not inform doctors and other professionals of the health any sign or strange symptom that their organism presents and may be harmful in their health, likewise they 
don't read or watch TV programs to improve their health, as well as they don't request information, don't get close don't ask questions or doubts to professionals in relation to their self-care, besides not exploring or examining their body at least every month to observe physical changes or signs and symptoms that might detect and generate a risk in their physical health. The healthy weight group also showed as a negative response that it's not looking for a second opinion, when putting into doubt the recommendations of the health promoter. These negative responses also show lifestyles with serious health problems.

Likewise, the dimension of physical activity prevails in the average behavior with a standard deviation of 1.66 in the overweight and obesity group and a score of 1.72 showing a low lifestyle for teenagers with a healthy weight. Both groups refer in the general that if they promote the physical activity unknowing some characteristics such as pulse monitoring when they do exercise, the healthy weight group refers that they don't follow a planned exercises program.

Also the stress management dimension the median of overweight and obesity teenagers was 1.72 and for the ones with healthy weight was 1.76 , it corresponds to the average lifestyle frequency. This dimension is considered healthy in both groups, except in the questions regarding with the specific methods to control the tension and who don't practice relaxation or meditation for 15 - 20 min daily, from 2 out of 8 items only 2 present low levels, considering that it is a healthy dimension before the stress management in this teenagers' groups.

Finally, the variable of spiritual growth resulted in a median of 2.16 in the group of overweight and obesity teenagers and a median of 1.88 in the group of healthy teenagers, which shows an average lifestyle. Spiritual growth in teenagers with lifestyle, overweight and obesity, is relatively healthy, provided that an answer rose with a low result in the control group, in which they find everyday interesting and challenging (stimulating).

We can see that in the six dimensions; interpersonal relationships, nourishment, physical activity, relations, stress management and spiritual growth, in the groups with healthy weight, an average lifestyle is provided, with scores from 1.54 to 1.88 . Considering this group as healthy, a positive result in their health isn't reflected. Nonetheless the group with overweight and obesity represent an average lifestyle in 5 of their dimensions; interpersonal relationships, nourishment, physical activity, relationships and stress management, that go from 1.40 to 1.80 , nevertheless there is a high level with a score of 2.16 in the dimension of spiritual growth, the latest means that teenagers with overweight and obesity are involved in their spirituality.

\subsection{Group Comparison in Study}

In relation of median comparisons in the dimensions of lifestyle is observed that there is a median of a score of 1.73 in the case group, and 1.68 in the group of controls, which shows that both teenagers groups have a healthy average lifestyle (Charts 4-6). 
Chart 4. Comparison of sizes in lifestyles dimensions.

\begin{tabular}{|c|c|c|c|c|c|c|c|}
\hline Group of teenagers & Interpersonal Relations & Nutrition & Health Responsibility & Physical Activity & Stress Management & Spiritual Growth & $\bar{X}$ \\
\hline Overweight and Obesity & 1.64 & 1.80 & 1.40 & 1.66 & 1.72 & 2.16 & 1.73 \\
\hline Healthy Weight & 1.54 & 1.76 & 1.40 & 1.72 & 1.76 & 1.88 & 1.68 \\
\hline
\end{tabular}

Source: Obtained data of HPLP instrument, 2019.

Chart 5. Variables association U of Mann-Whitney for independent samples in lifestyles dimensions.

\begin{tabular}{llll}
\hline & $n$ & & \\
\cline { 2 - 3 } Lifestyle Dimensions & 50 Teenagers & 50 Teenagers \\
Healthy Weight & Overweight and Obesity & 0.436 \\
\hline 1. Interpersonal Relations & 50 & 50 & 0.622 \\
2. Nutrition & 50 & 50 & 0.902 \\
3. Health Responsibility & 50 & 50 & 0.801 \\
4. Physical Activity & 50 & 50 & 0.919 \\
5. Stress Management & 50 & 50 & $\underline{\mathbf{5 0}}$ \\
6. Spiritual Growth & $\underline{\mathbf{5 0}}$ & & $\underline{\mathbf{0 . 0 4 6}}$ \\
\hline
\end{tabular}

Source: Obtained data of HPLP instrument, 2019.

Chart 6. Association U of Mann-Whitney for independent samples in lifestyles in teenagers with Healthy Weight vs Overweight and Obesity.

\begin{tabular}{cccc}
\hline & Teenagers & $n$ & Average range \\
\hline Lifestyles & Healthy Weight & 50 & 47.94 \\
& Overweight and Obesity & 50.282 & 53.06 \\
\hline
\end{tabular}

Source: Obtained data of HPLP instrument, 2019.

\subsection{Groups Association}

In the variables association there's no meaningful difference $(p>0.05)$ among the dimensions in health responsibility, physical activity, nourishment, spiritual growth and interpersonal relationships. In the spiritual growth lifestyle there is a significant difference $(p=0.046)$. There is no significant difference between the lifestyles in teenagers with healthy weight vs overweight and obesity. While the results are negative, it's important to determine that teenagers need an intervention of nursing to prevent complications, and have a healthy lifestyle in the adult age.

\section{Discussion}

Analyzing the lifestyles of teenagers with healthy weights versus overweight and obesity, is of great importance considering that in this study is shown that overweight and obesity in teenagers is increasing in the population of 12 to 15 years in Mexico with a high risk of complications in the adult life of the teenagers, generating a loss in healthy life years and an increase of health services, consider- 
ing that they are immersed in the dimensions: health responsibility, physical activity, nourishment, spiritual growth, interpersonal relationships and management of stress. The results obtained in this investigation show the lifestyles in two groups of populations in teenagers in a high school, similar to the National Survey of Health and Nourishment 2018 (NSHN 2018) in Mexico refers that, the combined prevalence of overweight and obesity in the teenage population was of $38.4 \%$ (IC 95\%).

According to Shapiro (2007), one of the biggest defender of the responsibility in health determines that the risks in health by the lifestyles are as willing as the people's choices, in the teenage there are biopsychosocial changes therefore they'll have the capability of having better choices regarding their health and equally responsible for the damage caused by the sickness itself. In Spain the article 14 of the Bioethics Universal Declaration and human rights introduces social responsibility and health; nevertheless, in Mexico there is no such norm that accounts responsible the teenager of his health, in this research a median average responsibility was obtained in both groups; the results are similar to a study performed in Colombia [18], this shows a great problem in the country.

The dimension of physical activity, presents an average score in both groups, similar to a study performed in Chile, nevertheless in a study performed in Colombia [18], presents a low median, in this country the prevalence of physical activity reports low percentages of the population that does physical activity which leads to encourage strategies and effective interventions nationally and internationally regarding physical activity to prevent complications and to improve quality life.

The nourishment focus is the most studied dimension as well as the physical activity. In a study performed in Spain [19], overweight and obesity is bigger in men than in women. Results in Mexico of the National Survey of Health and Nourishment 2018, expresses an increase of 3.5\% from 2012 to 2018. In one way or another it is observed that overweight and obesity in teenagers is increasing in the world countries.

The results in the dimension of spiritual growth in the group of overweight and obesity and in this kind of studies compared to the one of Treviño [18], report that there is a behavior of high spiritual growth, provided that students feel their life has a purpose, believe in a superior being, and feel at peace with themselves brings them tranquility, it is stablished that the current student may have bigger self-determination and self-regulation as Pender suggests. It's important to mention that there is a significant difference between both groups; it means that teenagers with overweight and obesity present a high level different from the group with healthy weight.

Interpersonal relations in teenagers is defined as a personal relationship when a person interacts with those with whom he keeps important effective relationships, like friends and relatives and they determine the context in the family environment as much as in the school environment [20] it means, the family environment affects in the personal relationships of the student, this study presents 
an average result that allows identifying that from the family there is a chaos in personal relationships which is reflected in a socio-school level In both groups.

Finally, as of stress management, the teenager by going through a stage of doubts and unknowing, he faces different situations that create stress. In a transactional stress focus, Lazarus and Folkman (1987), postulate that stress develops when the individual perceives in a subjective way an unbalance between the demands made and the resources with which he relies on to handle such demands, therefore the teenager presents stress, anxiety and a great unbalance in his mental health. In this study an average stress management is seen, presenting the unbalance this has and it's expressed with overweight and obesity as well as with a healthy weight, this is similar to a study performed in Colombia [18].

Pender, designed a model to prevent sicknesses, and they can get to a hospital for any complication, besides focusing maintenance for health. The professional in nursing may apply it to the many populations and can adopt a healthy lifestyle, now that in Mexico there is a low evidence in the use of the lifestyles instruments nowadays, therefore they are not lifestyles in the unhealthy studied group of teenagers.

\section{Conclusions}

In the study to analyze the lifestyles of the teenagers with healthy weight against the one with overweight obesity, it's allowed to identify that both groups present problems with healthy lifestyle in the studied dimensions, from which only the spiritual growth dimension presents a significant difference.

These results allow us to make decisions to improve the lifestyles in Mexican teenagers, like diagnostics and focused interventions to health promotion, encouraged to the behavior changes through orientation and orientation in the six dimensions. Pender recommends, if there is evidence and scientific proof that show the effectiveness of performed interventions by nurses in primary attention to health. In this way, learning environments are generated that lead to the acquisition of healthy habits and to prevent sicknesses and complications in adulthood.

\section{Conflicts of Interest}

The authors declare no conflicts of interest regarding the publication of this paper.

\section{References}

[1] Vargas, Z.M., Becerra, B.F. and Prieto, S.E. (2010) Evaluación de la Ingesta Dietética en Estudiantes Universitarios. Bogotá, Colombia. Revista de Salud Pública, 12, 116-125.

[2] Elswick, S., ÓDonnell, L., Dinon, N. and Rippe, J.M. (2011) Incorporación de la Medicina del Estilo de Vida en un Gran Sistema de Atención mÉdica: La Experiencia de Salud de Orlando. American Journal of Lifestyle Medicine, 5, 192-199. https://doi.org/10.1177/1559827610389131 
[3] García, T.M., Ibarra, O. and Roca, M. (2013) Los Hábitos de Vida Saludables Tienen un Efecto Antidepresivo. http://www.siicsalud.com/des/expertoimpreso.php/128894

[4] Márquez, D.X., Bustamante, E.E., Blissmer, B.J. and Prohaska, T.R. (2008) Promoción de la Salud Para un Envejecimiento Exitoso. American Journal of Lifestyle Medicine, 3, 12-19. https://doi.org/10.1177/1559827608325200

[5] Hyman, M.A., Ornish, D. and Roizen, M. (2009) Medicina del Estilo de Vida: Tratamiento de las Causas de la Enfermedad. Alternative Therapies in Health and Medicine, 15, 12-14.

[6] Walsh, R. (2011) Estilo de Vida y Salud Mental. American Psychologist, 66, 579-592. https://doi.org/10.1037/a0021769

[7] Harris, M.A., Oelbaum, R. and Flomo, D. (2007) Reseñas de Estado del Arte: Cambiar y Adherirse a los Cambios de Estilo de Vida. American Journal of Lifestyle Medicine, 1, 214-219. https://doi.org/10.1177/1559827606298979

[8] Lenz, T.L. (2010) Combinando la Medicina del Estilo de Vida con los Servicios de Administración de Terapia con Medicamentos en un Entorno de Farmacia Comunitaria. American Journal of Lifestyle Medicine, 4, 484-487. https://doi.org/10.1177/1559827610379557

[9] Lenz, T.L. (2011) Desarrollo de Una caja de Herramientas de Medicina del Estilo de Vida Para Promover el Cambio de Comportamiento de Salud. American Journal of Lifestyle Medicine, 5, 232-235. https://doi.org/10.1177/1559827610394394

[10] Aristizábal, H.G., Blanco, B.D.M., Sánchez, R.A. and Ostiguín, M.R.M. (2011) El Modelo de Promoción de la Salud. Enfermería Universitaria ENEO-UNAM, 8, 17-23.

[11] Instituto Nacional de Estadística y Geografía (2018) Encuesta Nacional de Salud y Nutrición 2018.

https://ensanut.insp.mx/encuestas/ensanut2018/doctos/informes/ensanut_2018_pre sentacion_resultados.pdf

[12] Organización Mundial de la Salud (2018) Prevención de la Violencia y el Jurado. Lesiones por Accidentes de Tránsito.

http://www.who.int/violence_injury_Prevention/road_trafÀc/en/

[13] García, R.C., Guillemb, F.C., Secoc, E.M., Gómez Puented, J.M., San José Arangoe, J., Manentf, J.I.R., Canterag, C.M., del Campo Giménezh, M. and Frauca, J.R. (2018) Recomendaciones Sobre el Estilo de Vida. Actualizacón PAPPS 2018. Atención Primaria, 50, 29-40.

[14] Raile, A.M. and Marriner, T.A. (2011) Modelos y Teorías en Enfermería. Séptima Edición, Barcelona, 434-453.

[15] Walker, S., Kerr, M.J., Pender, N.J. and Sechrist, K.R. (1990) Una Versión en Español del Perfil de Estilo de Vida que Promueve la Salud. Revista Enfermería, 39, 268-273.

[16] Triviño, Z., Stiepovich, J. and Merino, J. (2007) Factores Predictores de Conductas Promotoras de Salud en Mujeres Peri-Postmenopáusicas de Cali, Colombia. Colombia Médica, 38, 395-407.

[17] Walker, S.N. and Hill-Polerecky, D.M. (1996) Psychometric Evaluation of the "Health Promoting Life Style Profile 2". Payesh, 11, 849-856.

http://payeshjournal.ir/article-1-404-en.html

[18] Laguado Jaimes, E. and Gómez Díaz, M.P. (2014) Estilos de Vida Saludable en Estudiantes de Enfermería en la Universidad Cooperativa de Colombia. Hacia la 
Promoción de la Salud, 19, 68-83.

[19] Lorenzini, R. (2015) Estado Nutricional en Relación con el Estilo de Vida de Estudiantes Universitarios Mexicanos. Nutricion Hospitalaria, 32, 94-100.

[20] Zambrano, V.C. (2017) Violencia Intrafamiliar y Relaciones Interpersonales en los Escolares. Universidad Estatal de Milagro, Milagro.

https://www.redalyc.org/jatsRepo/5826/582661263012/index.html 


\section{Appendix}

\begin{tabular}{|c|c|c|c|c|c|}
\hline \multicolumn{6}{|c|}{$\begin{array}{l}\text { DIRECTIONS: This questonnaire contains statements about your present way of life or personal habits. } \\
\text { Please respond to each hem as accurately as possible, and ty not to skip any item. Indicate the frequency } \\
\text { with which you engage in each behavor by crraing: }\end{array}$} \\
\hline & \multicolumn{5}{|l|}{$\mathbf{N}$ for never, $\mathbf{S}$ for sometmes, $\mathbf{O}$ for often, or $\mathbf{R}$ for routinely } \\
\hline & & 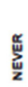 & 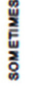 & 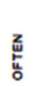 & 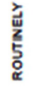 \\
\hline 1. & Discuss my problems and concerns with people dose to me. & $\mathbf{N}$ & $\mathbf{s}$ & 0 & $\mathbf{R}$ \\
\hline 2. & Choose a diet low in fat, saturated fat, and cholesterol. & $\mathbf{N}$ & $\mathbf{s}$ & 0 & $\mathbf{R}$ \\
\hline 3. & Report any unusual signs or symptoms to a physician or other health professional. & $\mathbf{N}$ & s & 0 & $\mathbf{R}$ \\
\hline 4. & Follow a planned exercise program. & $\mathbf{N}$ & $\mathbf{s}$ & 0 & $\mathbf{R}$ \\
\hline 5. & Get enough sleep. & $\mathbf{N}$ & $\mathbf{s}$ & 0 & $\mathbf{R}$ \\
\hline 6. & Feell am growing and changing in positve ways. & $\mathbf{N}$ & $\mathbf{s}$ & o & $\mathbf{R}$ \\
\hline 7. & Praise other people easily for their achievements. & $\mathbf{N}$ & s & 0 & $\mathbf{R}$ \\
\hline 8. & Limit use of sugars and food containing sugar (sweets). & $\mathbf{N}$ & $\mathbf{s}$ & 0 & $\mathbf{R}$ \\
\hline 9. & Read or watch TV progams about improving health. & $\mathbf{N}$ & $\mathbf{s}$ & o & $\mathbf{R}$ \\
\hline 10. & $\begin{array}{l}\text { Exercise vigorousy for } 20 \text { or more minutes at least three times a week (such as } \\
\text { brisk walking, bicyding, aerobic danding, using a stair dimber). }\end{array}$ & $\mathbf{N}$ & $\mathbf{s}$ & 0 & $\mathbf{R}$ \\
\hline 11. & Take some tme for relaxation each day. & $\mathbf{N}$ & s & o & $\mathbf{R}$ \\
\hline 12. & Belleve tha my life has purpose. & $\mathrm{N}$ & s & o & $\mathbf{R}$ \\
\hline 13. & Maintain meaningful and fulfiling relationships with others. & $\mathrm{N}$ & s & 0 & $\mathbf{R}$ \\
\hline 14. & Eat 6-11 senvings of bread, cereal, rice and pasta each day. & $\mathbf{N}$ & s & 0 & $\mathbf{R}$ \\
\hline 15. & Queston heal th professionals in order to understand their instructions. & $\mathbf{N}$ & $\mathbf{s}$ & 0 & $\mathbf{R}$ \\
\hline 16. & $\begin{array}{l}\text { Take part in light b moderate physical activity (such as sustained walking } \\
30-40 \text { minules } 5 \text { or more tmes a week). }\end{array}$ & $\mathbf{N}$ & $\mathbf{s}$ & 0 & $\mathbf{R}$ \\
\hline 17. & Accept those things in my life which I can not change. & $\mathbf{N}$ & s & o & $\mathbf{R}$ \\
\hline 18. & Look forward to the future. & $\mathbf{N}$ & s & o & $\mathbf{R}$ \\
\hline 19. & Spend time with dose friends. & $\mathbf{N}$ & $\mathbf{s}$ & 0 & $\mathbf{R}$ \\
\hline 20. & Eat $2-4$ senvings of frut each day. & $\mathbf{N}$ & $\mathbf{s}$ & o & $\mathbf{R}$ \\
\hline 21. & Get a second opinion when I question my health care provider's advice. & $\mathbf{N}$ & $\mathbf{s}$ & 0 & $\mathbf{R}$ \\
\hline 22. & $\begin{array}{l}\text { Take part in leisure-tme (recreationa) physical activities (such as swimming. } \\
\text { dancing, bicycling). }\end{array}$ & $\mathbf{N}$ & $\mathbf{s}$ & 0 & $\mathbf{R}$ \\
\hline 23. & Conoentrate on pleasant thoughts at bectime. & $\mathbf{N}$ & s & o & $\mathbf{R}$ \\
\hline 24. & Feel content and at peace with myself. & $\mathbf{N}$ & s & 0 & $\mathbf{R}$ \\
\hline 25. & Find it easy to show concern, love and warmth to others. & $\mathbf{N}$ & $\mathbf{s}$ & 0 & $\mathbf{R}$ \\
\hline
\end{tabular}

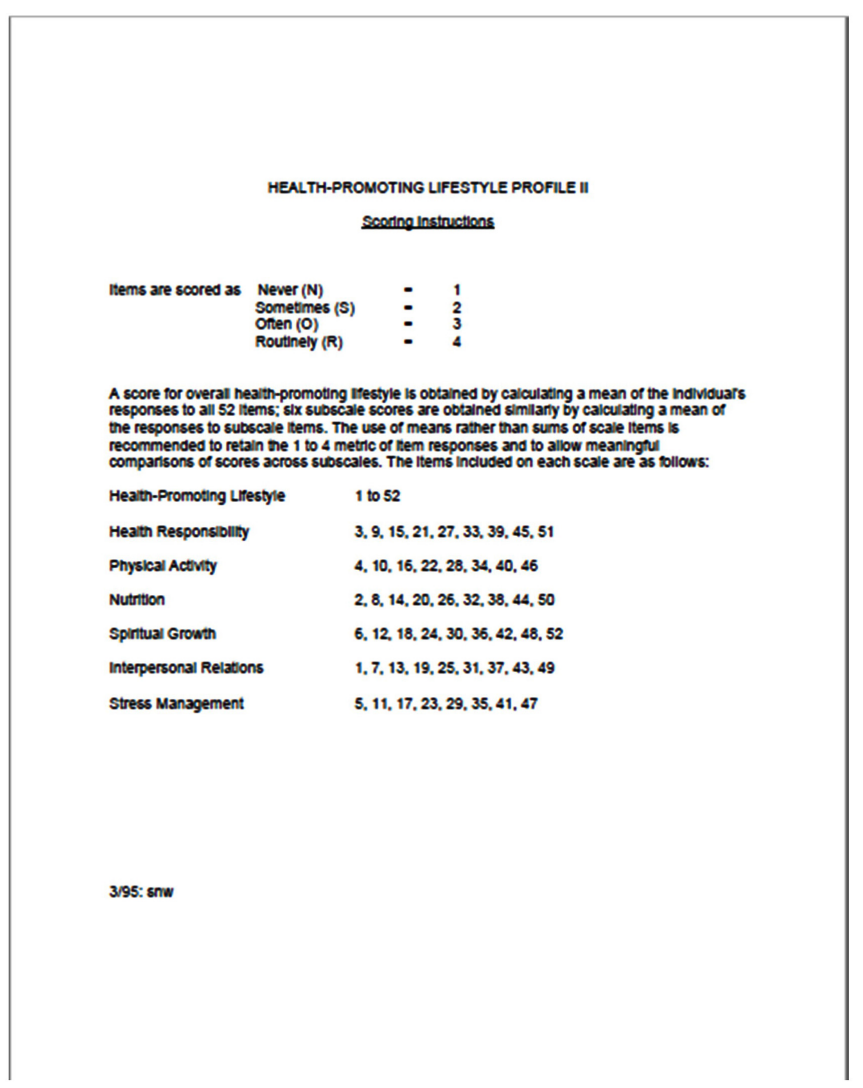




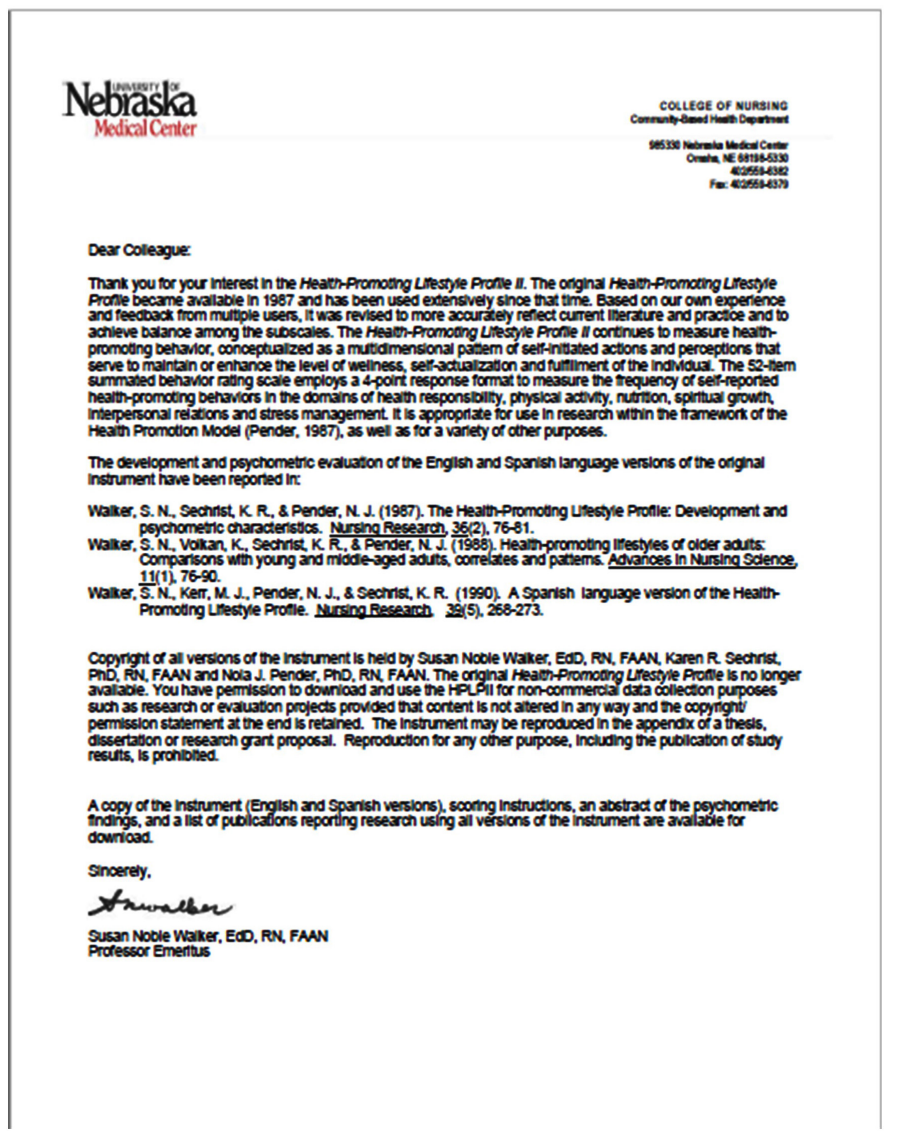

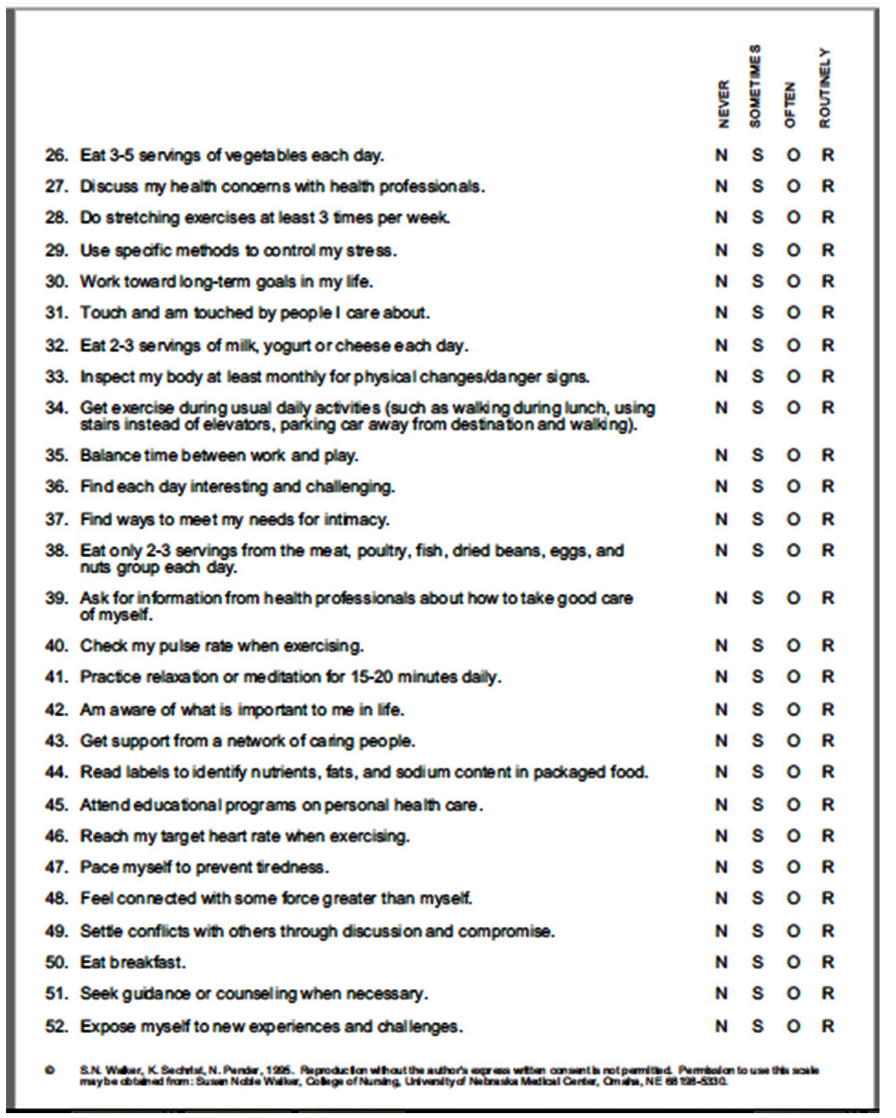

